Kehm, Barbara M.

Freeman, Richard P. J.

Locke, William

\title{
Growth and Diversification of Doctoral Education in the United Kingdom
}

\begin{abstract}
:
The chapter analyses the growth in numbers of doctoral students and doctoral degrees awarded in the UK in recent years and develops two arguments related to this growth. First, doctoral education and training no longer serves almost exclusively the reproduction of the academic profession but provides a highly qualified workforce for the knowledge intensive sectors of society. Second, due to the growth in the numbers, motives and purposes for obtaining a doctoral degree have diversified leading to the development of new routes towards a doctorate and an expansion in the types of doctoral degree.
\end{abstract}

The UK is probably the European country with the highest degree of diversity in terms of doctoral degree types and the most important ones are briefly described in the chapter. This second part will also include a brief discussion of non-academic labour markets for doctoral degree holders.

A third part of the chapter will look at the extended policy field into which doctoral education and training have increasingly been embedded in recent years. Given the fact that doctoral degree holders are a valuable resource (e.g. in human capital terms) for various economic sectors of the knowledge society, their education and training is no longer considered to be exclusively an academic affair. Instead, it is increasingly managed at institutional level and guided by policy processes at national and - at least in Europe - at supra-national level.

The fourth and final part of the chapter will discuss the question of the growing divergence or growing convergence in doctoral education and training. It is assumed that, despite the growing diversity of pathways and doctoral degree types there is also some convergence at play - at least at the European level - in so far as quality assurance, definitions of skills and qualifications as well as procedures for the examination and award of degrees are increasingly subject to standards, rules and regulations defined by the European network of quality assurance agencies. It remains to be seen whether the exit of the UK from the European Union will have an impact on, or even reverse, this trend. 


\section{Introduction: Reforms of Doctoral Education}

In recent years, the need to reform doctoral education and training has been high on the policy agenda in many countries around the world. The goal to increase the production of doctoral degrees is closely related to ambitions of gaining a competitive advantage in the global knowledge economy. Accordingly, national governments in Europe but also the European Commission have encouraged universities to increase the number of doctoral degrees awarded, recruit the best talent internationally for research training and structure this phase of qualification in such a way that doctoral degree holders have the necessary competencies and skills to work in non-academic as well as academic labour markets. This has led to a diversification of types of doctoral degrees and models of training. At the same time, quality issues in doctoral education and training are moving into the foreground of debates in order not to compromise the status of the degree.

In this chapter, we will first present some statistical overviews about the growth in numbers also looking at the gender balance and at the growing proportion of international doctoral students in the UK. Second, we will discuss the drive for greater transparency and accountability by monitoring supervision, completion rates and skills development. Third, we will offer some observations concerning the changed policy arenas but also the changing contexts for doctoral training and supervision. Fourth, we will look at the diversification of types and models of doctoral training describing a number of different pathways to the doctorate. Fifth, we focus on the increased attention to the student experience and student satisfaction as well as on the shift away from the thesis as a final product towards a greater concern with the development of the student. In the last part of the chapter before the conclusion we will focus on the evolution of the notion of the 'early career researcher'.

\section{Statistical Overview}

There are 126 doctoral degree-granting institutions in the UK (99 in England), all of which also award taught degrees (bachelor's and master's) and almost all of which are universities. There are no research-only institutions that award doctorates. There are a total of 164 higher education institutions (HEls) in the UK public HE sector.

In the last 50 years or so, there has been a dramatic rise in the demand for postgraduate study overall (including taught master's programmes) in the UK (Table 1). Some of this is due to increasing interest from outside the UK and, in particular, the recruitment of students from outside the European Union (EU). Since 1981, there has been no cap on the tuition fees that UK HEls have been able to charge non-EU students. Also during this period, the numbers of part-time postgraduates 
grew to exceed those studying full-time around the turn of the century, but have since been overtaken by the latter.

Table 1: Growth in numbers of all postgraduate students by mode of study, 1961-2015

\begin{tabular}{|l|l|r|r|r|}
\hline Date & Source & \multicolumn{1}{|c|}{ Full-time } & \multicolumn{1}{|c|}{ Part-time } & \multicolumn{1}{c|}{ Total } \\
\hline 1961 & Robbins, 1963 & 19,400 & 6,300 & 25,700 \\
\hline 1994 & Harris, 1996 & 128,300 & 187,100 & 315,400 \\
\hline $1999 / 2000$ & HESA, 2001 & 151,330 & 257,290 & 408,620 \\
\hline $2014 / 15$ & HESA, 2016 & 305,445 & 281,985 & 587,439 \\
\hline
\end{tabular}

Nearly $20 \%$ of those currently studying at postgraduate level are registered for research degrees, and an increasing proportion of these are full-time $(74 \%$ in $2014 / 15$, Table 2). The proportion of female doctoral students has also been steadily rising, from $45 \%$ in $2005 / 06$ to $47 \%$ in $2014 / 15$.

Table 2: Postgraduate research students 2010/11 to 2014/15

\begin{tabular}{|l|r|r|r|r|r|}
\hline & $\mathbf{2 0 1 0} / \mathbf{1 1}$ & $\mathbf{2 0 1 1 / 1 2}$ & $\mathbf{2 0 1 2} / \mathbf{1 3}$ & $\mathbf{2 0 1 3 / 1 4}$ & $\mathbf{2 0 1 4 / 1 5}$ \\
\hline Full-time & 74,790 & 78,975 & 79,680 & 81,940 & 83,720 \\
\hline Part-time & 29,070 & 30,090 & 29,445 & 29,555 & 29,190 \\
\hline Female & 48,345 & 50,865 & 51,130 & 52,355 & 53,485 \\
\hline Male & 55,510 & 58,195 & 57,985 & 59,105 & 59,390 \\
\hline UK & ${ }^{* *} 60,840$ & ${ }^{* *} 64,165$ & ${ }^{* *} 63,710$ & 64,110 & 64,375 \\
\hline Other EU & ${ }^{* *} 13,405$ & ${ }^{* *} 13,880$ & ${ }^{* *} 13,775$ & 14,500 & 14,870 \\
\hline Non-EU & ${ }^{*} 29,010$ & ${ }^{*} 30,270$ & ${ }^{*} 30,940$ & 32,880 & 33,655 \\
\hline All PGR ${ }^{\star}$ & $\mathbf{1 0 3 , 8 6 0}$ & $\mathbf{1 0 9 , 0 6 5}$ & $\mathbf{1 0 9 , 1 2 5}$ & $\mathbf{1 1 1 , 4 9 0}$ & $\mathbf{1 1 2 , 9 1 0}$ \\
\hline
\end{tabular}

* Totals include those for whom sex, mode of study and domicile was not known

** Data from HESA, 2012, 2013 and 2014 which do not match with totals given in HESA 2016

HESA 2016

In $2014 / 15$, nearly 23,000 doctorates were awarded in the UK, with two thirds (66\%) being in science, medicine, engineering, technology and mathematics, $20 \%$ in social sciences and $14 \%$ in humanities and the arts (Table 3 ). 
Table 3: Doctorates obtained by subject of study, 2014/15

\begin{tabular}{|l|r|c|}
\hline Subject of study & Number & Proportion \\
\hline Medicine \& dentistry & 2,260 & $10 \%$ \\
\hline Subjects allied to medicine & 1,340 & $6 \%$ \\
\hline Biological sciences & 3,395 & $15 \%$ \\
\hline Veterinary sciences & 65 & $0.3 \%$ \\
\hline Agriculture \& related subjects & 200 & $0.9 \%$ \\
\hline Physical sciences & 2,845 & $12 \%$ \\
\hline Mathematical sciences & 665 & $3 \%$ \\
\hline Computer sciences & 910 & $4 \%$ \\
\hline Engineering \& technology & 2,970 & $13 \%$ \\
\hline Architecture, building \& planning & 380 & $2 \%$ \\
\hline Social studies & 1,930 & $8 \%$ \\
\hline Law & 430 & $2 \%$ \\
\hline Business \& administrative studies & 1,150 & $5 \%$ \\
\hline Mass communications \& documentation & 215 & $0.9 \%$ \\
\hline Languages & 1,215 & $5 \%$ \\
\hline Historical \& philosophical studies & 1,310 & $6 \%$ \\
\hline Creative arts \& design & 645 & $3 \%$ \\
\hline Education & 850 & $4 \%$ \\
\hline Total - All subjects & $\mathbf{2 2 , 7 7 5}$ & ${ }^{*} \mathbf{1 0 0 . 1} \%$ \\
\hline
\end{tabular}

${ }^{*}$ Total percentage is not 100 due to rounding up and down

HESA, 2016

$56 \%$ of all those obtaining a doctorate in $2014 / 15$ were from the UK, $14 \%$ from another EU country and $30 \%$ from outside the EU (Table 4). $82 \%$ had been full-time doctoral students and $18 \%$ part-time. UK doctoral students were more likely to have studied part-time than those from outside the UK and, of those from the UK, females were more likely to study part-time than males, whereas males were more likely to study full-time.

Table 4: Doctorates obtained by sex, domicile and mode of study, 2014/15

\begin{tabular}{|c|c|c|c|}
\hline & Female & Male & Total \\
\hline \multicolumn{4}{|l|}{ Full-time } \\
\hline UK & 4,695 & 5,110 & 9,805 \\
\hline Other EU & 1,250 & 1,375 & 2,625 \\
\hline Non-EU & 2,600 & 3,700 & 6,300 \\
\hline Total full-time & 8,545 & 10,185 & 18,755 \\
\hline \multicolumn{4}{|l|}{ Part-time } \\
\hline UK & 1,605 & 1,440 & 3,050 \\
\hline Other EU & 215 & 225 & 440 \\
\hline Non-EU & 225 & 295 & 520 \\
\hline Total part-time & 2,045 & 1,960 & 4,025 \\
\hline
\end{tabular}

* Totals include those for whom sex, mode of study and domicile was not known 


\section{The Drive for Greater Transparency and Accountability}

The first UK PhD was awarded - by the University of Oxford - in 1917 (in typically idiosyncratic style, it was termed a DPhil, a usage that endures still). Within five years, there were $774 \mathrm{PhDs}$ awarded and double that number in the following five years across more than a dozen universities (Simpson, 1983). The two main waves of university expansion - the introduction of so-called "red brick" universities in the 1960 s and the conversion of polytechnics to universities in 1992 - had minimal impact on the form of the PhD. The PhD thesis could be seen as an 'apprentice piece' produced by an apprentice to a master (who was able to produce a 'masterpiece') who supervised the process with little institutional input.

However, in the early twentyfirst century, as part of the new Labour government's focus on a skills agenda, the $\mathrm{PhD}$ began to change. The focus on the development of skills as part of PhD study was driven by Sir Gareth Robert's SET for success: The supply of people with science, engineering and mathematics skills (Roberts, 2002). Roberts famously stated that "The product that the PhD researcher creates is not the thesis - vital though that is to their subject area through the creation of original knowledge - no, the product of their study is the development of themselves."

In addition, in 2001 the Joint Skills Statement was published by the UK Research Councils which set out seven areas that doctoral research students they funded would be expected to develop during their research training. To support this, the UK government provided approximately £20 million a year in ring-fenced funding ("Roberts Money") to Research Councils UK (RCUK), universities and other research council funded institutions. The sums provided to each institution depended on the number of research council funded students and research staff. Some institutions received over £1 million per year and some just a few hundred pounds (Hodge, 2010). The funding was made available from 2004 until 2011 to support the career development and transferable skills training of researchers. Research Council funded students are now expected to undertake the equivalent of two weeks of skills training per year and most institutions require all their doctoral students to do the same.

To support the necessary institutional changes, in 2002 RCUK funded CRAC (The Career Development Organisation) to create the UK GRAD Programme to support the academic sector to embed personal and professional skills development into research degree programmes (together with a similar body for those supporting research staff - UK HERD - Higher Education Research Development) alongside eight regional hubs. In addition to developing resources, UK GRAD supported residential 'GRADschools' where students could meet other doctoral researchers from a range of disciplines and develop their professional and personal effectiveness 
and engage in career planning for academic and non-academic careers. In 2008, UK GRAD and UK HERD were merged into a new organisation, Vitae (www.vitae.ac.uk), with financial support from RCUK. Since 2014, Vitae has been funded by universities and research institutions, both UK and international.

In 2010, all the skills and attributes of the Joint Skills Statement were incorporated within the Researcher Development Statement (RDS) that sets out the knowledge, behaviours and attributes of effective and highly skilled researchers appropriate for a wide range of careers - making explicit the continuity expected between doctoral training and subsequent career development. The RDS has been implemented as the Vitae Researcher Development Framework (https://www.vitae.ac.uk/researchersprofessional-development/about-the-vitae-researcher-development-framework) with four top-level domains (A: Knowledge \& Intellectual Abilities; B: Personal Effectiveness; C: Research Governance and Organisation; D: Engagement, Influence \& Impact), twelve sub-domains (A1. Knowledge base; A2. Cognitive abilities; A3. Creativity; B1. Personal qualities; B2. Self-management; B3. Professional and career development; $\mathrm{C} 1$. Professional conduct; $\mathrm{C} 2$. Research management; C3. Finance, funding and resources; D1. Working with others; D2. Communication and dissemination; D3. Engagement and impact, and 63 descriptors.

The necessary involvement of others beyond the supervisor has led to what Chris Park calls an end to the 'Secret Garden' of supervision (Park, 2006). Instead the student is now seen as having networks of support, including librarians, career advisors and an emerging profession of "researcher developers" who were initially largely funded by Roberts Money, but are now part of the established staff of most universities that have research students and/or research staff. The extra funding to support PhD students was accompanied by formal monitoring of progression and completion of doctoral degrees with the first official report finding that almost seven years after registration $71 \%$ of full-time students and $37 \%$ of part-time students had gained an MPhil, PhD or both (HEFCE, 2005). The Higher Education Act 2004 that raised undergraduate fees also led to the creation of an independent body to deal with student complaints, which became the Office of the Independent Adjudicator (OIA). The OIA deals with complaints from all students and notes that "As in previous years, ... postgraduate students are disproportionately likely to complain", accounting for $8 \%$ of the 1,850 complaints submitted in 2015 (OIA, 2015).

\section{Changing Contexts and Policy Arenas}

Increasingly the production of new knowledge, often a task and an aspiration of doctoral candidates, is no longer regarded as a purely academic affair but as a strategic resource in the emerging knowledge societies. With this shift, doctoral education and training has become an object of institutional management, of national policy as well as support or funding programmes, and of supra-national incentives, 
regulations and measures for better integration into the existing knowledge and innovation systems. Furthermore, an increasingly international competition for best talent has begun (Kehm 2006: 67).

At the same time, public criticism of doctoral education and training has become louder: too long, too many drop-outs, too specialized, questionable quality of supervision, lack of competences for non-academic labour markets. The continental European answer to such criticism was "structured doctoral education", i.e. the integration of this qualification phase into programmes, centres, schools or colleges, etc. and the addition of systematic curricular provision to offer theoretical, methodological and labour market related competences to the research work on the dissertation. In the UK, the seven Research Councils have introduced programmes for managing their funding of doctoral study, including 'Doctoral Training Centres' (DTCs)/'Centres for Doctoral Training' (CDT) and 'Doctoral Training Partnerships' (DTPs). In contrast to conventional individualised supervision, each DTC/DTP is hosted by a UK university (or increasingly a consortium of universities, and sometimes other partners such as museums or related industries), which delivers doctoral training programmes to a large number of PhD students divided into cohorts. The programmes can include linked Masters and PhD $(1+3$ years of fulltime study), a combination where PhD study begins alongside Masters training (but not assessment (4 years of full-time study), PhD study alone (3 years of full-time study) and other models where specialized training is required, e.g. learning a language. The student's registration fees are paid, the student receives a tax-free stipend with supplements for those studying in areas identified as strategic priorities and the student is able to apply for funding for conference attendance, overseas study, public engagement activities etc.

Each DTC/DTP focuses on a specific area of research, and also provides transferable skills training. This development has currently three observable consequences: First, the dominant master-apprentice model is beginning to be phased out; second, the focus on a point in the framework of a rite of passage (i.e. defence and award of title) with an emphasis on the product "dissertation" is shifting to a focus on the process of doctoral education and training (its structures, content, quality) and on the development of the student towards becoming a researcher; third, access to doctoral education and the process of getting a doctorate are increasingly embedded in a dense layer of regulations, criteria, defined rights and obligations, procedures of evaluation and controls of success (Kehm 2006: 73).

In the framework of the European Bologna Process, the phase of getting a doctoral degree has also become a much discussed topic. The reform initiators (ministers for higher education from 27 , later 46 European countries) initially conceptualised doctoral education as a third cycle of studies in the framework of which seminars had to be taken and credit points earned. However, this conceptualisation as a third cycle of studies met with resistance from a number of European countries. Such a concept was only valid in those European countries in which doctoral candidates were 
traditionally regarded as students and had to pay fees for supervision and seminars (as in the UK) or in countries in which graduate studies follow a Bachelor's degree. Such a concept did not fit at all in those European countries (the Nordic countries and Germany among them) in which eligibility for doctoral education is only granted after a Master degree and in which doctoral education and training takes place predominantly in the framework of employment contracts as research assistants or junior academics and is understood as a first phase of an academic or research career (in Sweden, for example). However, in the meantime, the structuring of doctoral degrees has found many supporters. Despite the fact that the organisational forms as well as the terminology (e.g. graduate college, graduate centre, doctoral training centre, doctoral programme) continue to proliferate, it is hoped in principle that structuring the doctoral phase will solve a number of problems (Kehm 2006).

Also in the context of the European Bologna Process, new issues have been raised. First among these is the better preparation of doctoral candidates for non-academic labour markets because a growing proportion of doctoral degree holders will not remain within a higher education institution or an extra-university research institute.

A second issue is that academic staff are increasingly made responsible for the success of the doctoral candidates they supervise. In some European countries (e.g. in Spain) regulations have been introduced which define who can act as a supervisor (no longer every academic) and what kinds of formal qualifications and further criteria must be obtained and fulfilled in order to have the right to supervise doctoral candidates (for example, some kind of further professional qualification in supervision or a minimum number of research projects and publications). This trend has an impact on the degree of selectivity in terms of the access and admission of doctoral candidates.

Thirdly, there are issues pertaining to the meaning of "critical mass" in the framework of ongoing discussions about efficiency and effectiveness. This means that at quite a number of European universities criteria are established to determine (a) how many academics a university should have in a given field or discipline in order to offer optimal conditions for doctoral candidates, and (b) how many doctoral candidates a given doctoral programme, doctoral school or doctoral college should have ideally (or minimum and maximum numbers). These numbers can differ from subject to subject but we can observe concentration processes with consequences for smaller subjects and for a further institutional differentiation into research universities with the right to award doctoral degrees and teaching universities without this right (Kehm, 2004, 2005, 2006, 2007).

As mentioned before, doctoral education and training is no longer an exclusively academic affair but has become an object of institutional management as well as national and supra-national policy-making. The inclusion in 2003 of doctoral education as a third level or cycle of a tiered structure of studies and degrees in the framework of the Bologna Process was, among other things, a consequence of the 
European Council's and Parliament's strategy in the year 2000 to create a common European Research Area (Lisbon Summit 2000). This strategy was supposed to develop Europe into the most dynamic knowledge-based economy in the world in order to be globally competitive. To achieve this, the number of doctoral degree holders was to be increased and doctoral candidates were supposed to become better prepared for non-academic labour markets. The descriptors for the doctoral level of the European Qualifications Framework clearly reflect this.

Focusing on the national policy field, in most European higher education systems we can observe an increasing number of initiatives and support programmes to establish a structure for doctoral education and training. The number of doctoral degrees awarded has become an indicator included in performance based funding and budgeting in intra-institutional budget allocations. National policy, by and large, is in favour of increasing even further the number of doctoral degree holders because it is believed that a large number of people with high qualifications provide a competitive advantage for the economy on a global scale.

The institutional policy field has also changed with regard to the indicator "doctoral degrees". Almost all universities encourage their academic staff as well as faculties and departments to increase the number of doctoral degrees awarded and to reduce the 'time-to-degree'. The number of doctoral degrees awarded is an important indicator when measuring research output as in the Research Excellence Framework, in the context of establishing a profile and reputation as a researchintensive institution, and in the framework of the general competition for reputation and funds. But there is a further intra-institutional dimension. Within universities, competition has also become stronger and departments, research groups or individual academics who have been particularly successful in terms of doctoral education and training can negotiate for extra funds or other material advantages (e.g. additional human resources or better infrastructure). Traditionally a high number of successful doctoral students has contributed to the individual reputation of a given academic within their disciplinary community. This continues to be the case, however, it is reinforced by the contribution this makes to the reputation of the institution. In the UK, a special emphasis is placed on attracting full tuition fee-paying international doctoral students from outside the EU in order to generate institutional income.

In the UK, the Doctoral Training Centres (DTCs) were initially designed to support interdisciplinary scientific research to solve global issues such as the ageing population and energy security. The model was subsequently adopted by the social sciences and humanities and, in the former, all of the research council (Economic and Social Research Council) funding for doctoral studentships has been allocated to the 21 accredited social science DTCs. In 2016, these were replaced by 14 larger Doctoral Training Partnerships with wider membership to include 'pockets of excellence' at non-research intensive universities. Through these means, the Research Councils seek to provide a steer to doctoral training, raise quality and 
stimulate innovation. The DTCs/DTPs are monitored and evaluated by the Research Councils and this has informed the development of national postgraduate training strategies.

\section{Diversification of Types and Models of Doctoral Degrees}

If we look at the changes from a European perspective, we can see that the models of doctoral education and training, and with them their goals and purposes, have multiplied in recent years. This has progressed furthest in the United Kingdom. Mostly, we find an increasing differentiation between a research doctorate and a professional doctorate. Further research has yielded nine different models which will be introduced here briefly (Kehm 2009).

\section{The Research Doctorate}

For the research doctorate, the dissertation is central and expected to be an original contribution to the knowledge base of a discipline or a research domain. Regardless of whether the degree (or title) is acquired within a structured programme including course work, or in a master-apprentice relationship, the research doctorate as a rule is an entrance ticket to the academic profession which - by being responsible for the training - also has a gatekeeper function. Using the example of six disciplines, Golde and Walker (2006) have characterised the main purpose of doctoral education in the research doctorate as developing students to be "stewards of the discipline". The goal of such a training is a scientific or scholarly ideal type characterised as someone "who can imaginatively generate new knowledge, critically conserve valuable and useful ideas, and responsibly transform those understandings through writing, teaching and application. A steward is someone to whom the rigour, quality, and integrity of the field can be entrusted" (Golde and Walker, 2006:5). This rather normative image contrasts starkly with the image generated by Slaughter and Leslie (2000) of the successful academic as "capitalist entrepreneur" who has recognised the demands and challenges of market orientation, competition and globalisation in the emerging knowledge societies and knows how to draw advantages from these developments.

\section{The Professional Doctorate}

A number of European countries have picked up the British trend to explicitly distinguish between a research doctorate and a professional doctorate. The professional doctorate is not awarded in all disciplines but restricted to subjects like business administration, medicine and health care, education, engineering, social work etc., i.e. to subjects which have a relatively demarcated field of professional 
practice. In professional doctorates, the title usually includes an indication of the professional field (e.g. DBA for Doctor of Business Administration or EdD for Doctor of Education). Quite a number of publications have appeared in recent years on the professional doctorate (Bourner, Bowden and Laing 2001, Park 2005 and Green and Powell 2005). To some extent this seems to be related to the fact that, in academic circles, the professional doctorate is often looked down upon as a second class doctorate so that pressure for legitimation increased.

The professional doctorate is defined as a programme of advanced studies which apart from fulfilling university criteria for the award of the degree - is geared towards satisfying a particular demand from a professional group outside the university and towards developing research skills needed within a professional context (Bourner, Bowden and Laing, 2001: 219). In the United Kingdom, professional doctorates are typically taken up by people who are pursuing a professional career and are employed. Therefore, professional doctorates are frequently offered as part-time programmes and usually require several years of professional experience. Tuition fees are often covered fully, or in part, by the employer. The target group often wants to gain the degree in order to be eligible for promotion in their professional field. Consequently the research work carried out for the dissertation is regarded less as a contribution to the knowledge base of a discipline but more as a contribution to the development of a professional domain. The dissertation then has a focus on the generation of new but more applied knowledge (with data collection sometimes taking place in the student's workplace) and the topic is often generated from the respective professional practice. In some areas, e.g. in engineering the dissertation can also have the form of a larger project, or series of smaller projects, which are carried out in the framework of actual professional practice.

\section{The Taught Doctorate}

By definition, the taught doctorate consists of a substantial proportion of course work. Typically there will be a fixed curriculum and learning outcomes will be graded and weighted for the final grade. As in the research doctorate students are supposed to contribute to the generation of new knowledge but they do this in the framework of a research project the results of which are summarised in a project report. The report is presented in the framework of an oral examination and is graded as well. In contrast to the two-phase doctorate in the United States (course work first, then research and writing of thesis), the course work of the taught doctorate is spread over the whole period of degree training (predominantly offered in the United Kingdom). The oral examination and the grade of the research project report are regarded as an equivalent to a dissertation and its defence. 
The model of the PhD by published work has existed in Germany since the $19^{\text {th }}$ century (where it is called a "cumulative dissertation"). From there it spread to other parts of the world, mainly the United States but also to Belgium, to the Netherlands and to Sweden. At a second glance, the British model of the PhD by published work differs to some extent from the German model of a "cumulative dissertation". Both models are basically characterised by combining several articles which have appeared in peer reviewed scholarly or scientific journals into a book and providing them with a coherent framework. But while this option is open for many candidates in Germany, the PhD by published work is awarded in the United Kingdom almost exclusively to employees or alumni of the university awarding the degree (Green and Powell, 2005:72).

This model has frequently been criticised for its lack of consistency, differences in the definition of what constitutes a publication, its threat to other forms of doctoral education, and the problems of providing adequate supervision. Furthermore, in this model of the doctorate, it is predominantly the product which is evaluated and graded and not the process of getting the degree itself. Therefore, most countries that provide this opportunity have regulations in place which determine the character and the content of the dissertation and possibly also the question whether and in which form a programme of additional studies has to be taken (Green and Powell, 2005: 71).

\section{The Practice Based Doctorate}

The practice based doctorate is unique to the British university system, although it is also awarded in Australia. It denotes the award of a doctoral degree in the Arts and in Design.

The practice based doctorate increased in importance with the integration of colleges of art into the universities in the 1990s in the United Kingdom. The degree is awarded as a result of course work undertaken when students have been familiarised with theories and research methodologies, and takes the form of a presentation of a work of art or a performance as a substitute for the dissertation. The presentation or performance is accompanied by a text in which the candidate explains how he or she has arrived at the result or product by applying research methods. This is regarded as generating new knowledge through practice. Successful candidates are also expected to demonstrate how their work of art is related to other works of art in the same field (by providing a theoretical, historical, critical, or visual context) and to evaluate possible effects. In the field of composition, frequently not just one work is presented but a whole portfolio. In the oral examination, the work of art is presented or performed and the candidate demonstrates on the basis of the accompanying text that she or he has sufficient knowledge and appropriate skills to independently generate new knowledge. 
The practice based doctorate is contested in the United Kingdom because compared to all other models of the doctorate - it shows the least proximity to the traditional notion of a dissertation. However, about half of all British universities offer such a doctorate (Green/Powell 2005:100ff.).

\section{The "New Route" Doctorate}

The model of the "new route PhD" (also called the integrated doctorate) was developed by ten British universities as a form of brand name in 2001 with the purpose of attracting international students. Since then, it has been offered by more than 30 British universities. The programme basically consists of three (integrated) elements: a taught component in the area of research methods and subject specialisation, another taught component in the area of transferable skills and the work on a dissertation (disciplinary or interdisciplinary). Admission can be granted immediately after a student has completed a Bachelor's degree. The taught components are frequently offered in the framework of related Master programmes and accompany the whole four years envisaged for obtaining the degree. For the taught components, 240 credit points are awarded. Requirements for the dissertation are of a similar level to the research doctorate (www.newroutephd.ac.uk).

However, in comparison to the research doctorate, the taught elements are more important and also prescribed in more detail with respect to the qualifications and competences to be acquired. After having finished all the course work there is also the option to write a master's thesis instead of a doctoral dissertation and complete with a master degree.

In effect, the new route $\mathrm{PhD}$ follows the American model of an integrated postgraduate education in which the master's level and the doctoral level are combined in terms of the course work to be done. However, the American model clearly separates the course work phase from the writing of a thesis which follow each other in sequence and are not integrated. This American two-phase approach results in high drop-out rates after completion of the course work or (compared to Europe) a longer time to complete the degree (between six and nine years). Despite the fact that a fast track to the doctoral degree is possible in exceptional cases in many European countries, the European University Association (EUA) has recommended that the Master's degree should constitute the minimum requirement for access into doctoral programmes or the doctoral qualification phase (see EUA-

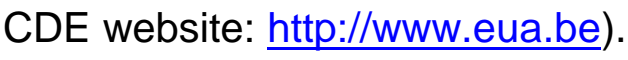

\section{Two Models of the Joint Doctorate}

The model of the joint doctorate is characteristic of doctoral programmes jointly offered by two or more universities which may be located in the same region, the 
same country or in different countries. A study carried out by EUA (EUA, 2005) about changes in doctoral education in Europe included a survey among member institutions. 18 per cent of responding universities confirmed that they offer joint doctorates. Leading countries in terms of the number of joint doctoral degree programmes are Germany, Spain, France, Italy, the United Kingdom and the Netherlands.

In the EUA study (EUA 2005: 28ff.), the joint doctorate is characterised as follows:

a joint curriculum for the taught components which has been developed in close cooperation among the participating institutions; the doctoral students take courses at several universities;

an agreement signed by all participating institutions clarifying funding issues and other matters (e.g. mobility, quality assurance).

Certification of a joint doctorate is regulated in various ways: from award of the degree from the university at which the candidate is enrolled, to a double degree on the basis of joint supervision (i.e. co-tutelle arrangements) and a joint degree.

Joint doctorates are predominantly awarded by universities (or more exactly by faculties and departments) cooperating in transnational networks. The advantages for doctoral students are that, in most cases, periods of mobility are built into the programme, they often have more than one supervisor and access to additional experts in their field who are members of the network. However, actual practice may differ from this ideal type. Joint doctorates have a higher degree of internationalisation and more opportunities for mobility, but they are often not based on a joint curriculum of the participating partner institutions.

A particular variant of the joint doctorate is the "European doctorate". The idea and an informal initiative arose at the beginning of the 1990s during a meeting of the Confederation of European Rectors' Conferences (an organisation which has merged with the former CRE to become the EUA). The "Doctor Europaeus", as this was originally to be titled, is still contested, although there is a consensus about promotion and improvement of European cooperation in doctoral education and the mobility of doctoral students (or candidates). Currently another initiative with similar aims is being undertaken by the European Commission, which offers funding for joint doctoral programmes emerging from partner universities of an Erasmus Mundus Programme. The difficulty in putting this idea into practice is due to the fact that within Europe there is an increasing competition for the best talent among institutions and at the national level a more competitive research policy and innovation strategy. Thus, best talent is not easily "shared". Nevertheless, the discussion about the "Doctor Europaeus" has been revived in the context of the Lisbon Strategy to create a European Research and Innovation Area (EUA, 2005) and several Italian universities are currently offering it. 


\section{The industrial doctorate}

The industrial doctorate is mostly awarded in engineering fields and is a more applied degree. The research work of the candidate is carried out for example, in the research and development department of a company and is oriented towards the solution of a particular problem or issue. The research is supervised by a senior engineer of the company while taught elements, theory and methodology are supervised by a university academic. Research topics frequently emerge from work undertaken by the student in that company during an internship.

\section{The Student Experience}

As with undergraduate education, there has been a growing interest in the experience of doctoral students of their supervision and the environment in which they are studying. Following the National Student Survey (NSS) of final year undergraduates launched in 2005, the Postgraduate Research Experience Survey (PRES, alongside the Postgraduate Taught Experience Survey or PTES) was established in 2007. The biennial survey administered by the Higher Education Academy asks research students about their experiences of:

- $\quad$ supervision

- resources

- $\quad$ the research community

- $\quad$ progress and assessment

- $\quad$ skills and professional development

It also considers students' motivations for undertaking their studies and collects demographic information. In 2015, 53,348 students responded from 123 institutions (Turner, 2015).

Unlike the NSS (but more like the National Survey of Student Engagement in North America), higher education institutions opt into the survey and the results are not published, but available to participating institutions in an anonymised format as well as a summary report (e.g. Turner, 2015). Institutions use the PRES results to benchmark their provision against others in the sector. Results can be broken down by discipline, gender, mode of study and home/other EU/non-EU student domiciles, with the aim of targeted improvements where they are most needed. In the UK, the results are used to inform sector bodies and policy makers about what students can expect across the country. Currently, there is a consultation on possible changes to the PRES survey, covering the relevance for Doctoral Training Centres and professional doctorates, and whether the results should be fully published.

\section{The Notion of 'Early Career Researcher'}


As the achievement of a doctorate has become increasingly necessary, but no longer sufficient, for an academic career, so the notion of the 'early career researcher' has developed to describe that period of transition between doctoral study and an established and independent position in the profession. Many of the UK research councils have set criteria for funding schemes aimed at 'early career researchers' that limit the number of years after the doctoral award that a researcher can apply, for example, usually four years in the case of the Economic and Social Research Council (ESRC). However, there is a realisation that individuals take different routes in their transition to independence, so the ESRC now refers to years of "active postdoctoral experience". In calculating that 'active' experience, the ESRC makes allowance for periods where the applicant has interrupted their career for family, health or other personal reasons as well as those returning to research following a career break.

One research council, the Medical Research Council, has recently removed the eligibility criteria based on years of post-doctoral experience for its Fellowships scheme and New Investigator grants. The criteria now refer to the skills and experience that applicants are required to demonstrate in applying for these funds in order to be competitive. This is likely to help those caught in a succession of fixedterm post-doctoral positions. This categorisation of 'early career researcher' is also being widened to include those who have graduated into non-academic employment, and who may move into academia at some later point in their career.

\section{Conclusions}

The proliferation of types and models of doctoral education and training described above is an indicator of new forms of functional differentiation in doctoral education and training resulting from an increased number of doctoral candidates and their more diverse interests and motives. Doctoral education no longer serves exclusively the reproduction of the academic profession but has also become a qualification for knowledge intensive non-academic sectors of the economy and for steps up the professional career ladder.

However, these developments have also triggered some criticism (see overview in Park 2005: 201). The four main points of criticism can be summarised as follows:

- Other models than the research doctorate tend to be regarded as second class doctorates. The quality of the dissertation as well as the quality of the process of getting the degree are often ranked lower than the research doctorate.

- External examiners have noted - in particular, with respect to practice based doctorates - a lack of intellectual depth, of cohesion, of discussing existing literature, of originality and generalisable results of the work. In addition, they have criticised methodological weaknesses and bad presentation. 
- Bourner, Bowden and Lang (2001) criticised the new types of doctorates as often lacking clarity and coherence.

- Some experts have also voiced concerns about the growing proliferation of titles and the increasing differentiation of types and models.

Supporters of the growing differentiation of doctoral models have argued that it reflects the growing heterogeneity of reasons for obtaining a doctorate and these should be taken into account when shaping this phase of qualification.

In drawing this chapter to a close, we would make one further observation. In continental Europe, as well as in many other countries around the world with wellestablished and mature higher education systems, the doctorate is no longer the entrance qualification to an academic career. It is a necessary but insufficient condition and decisions as well as selection processes have shifted into the 'postdoc' phase. However, a doctoral degree nowadays tends to qualify the holder for a rather wider range of jobs as a knowledge worker in non-academic labour markets.

Certainly, doctoral candidates today are no longer exclusively trained to become "stewards of their discipline" (Golde and Walker 2006) as was the case until the end of the 1980s and in some European countries until well into the 1990s. The extended policy field for doctoral education and training has contributed to the fact that doctoral candidates today need to acquire a considerably broader set of skills and competences. Doctoral degree holders are not only in demand in the knowledge intensive sectors of the economy but in other fields, e.g. services, public administration, media, etc., as well. Having observed this, however, two questions remain which still need further research and debate. The first is, who within the universities has the knowledge and skills to convey this extended skills set? The second is, whether academic careers in Europe, with their extended periods of uncertainty and even precarity, continue to remain sufficiently attractive to attract the best and the brightest.

\section{References}

Bologna Declaration (1999): http://www.aic.lv/ace/ace disk/Bologna/maindoc (accessed 7 October 2005)

Bourner, Tim, Bowden, Rachel and Laing, Stuart (2001): "Professional Doctorates in England". In: Studies in Higher Education, Vol. 26, No. 1, p. 65-83

Burkhardt, A. (Hg.) (2008): Wagnis Wissenschaft. Akademische Förderwege und das Fördersystem in Deutschland. Leipzig: Akademische Verlagsanstalt. 
EUA (2005): Doctoral Programmes for the European Knowledge Society. Brussels. URL: http://www.eua.be/eua/jsp/en/upload/Doctoral Programmes Project Report.112927 8878120.pdf (accessed: 1 November 2005)

Golde, Chris M. and Walker, George E. (eds.) (2006): Envisioning the Future of Doctoral Education. Preparing Stewards of the Discipline. Carnegie Essays on the Doctorate. San Francisco: Jossey-Bass

Green, Howard and Powell, Stuart (2005): Doctoral Education in Contemporary Higher Education. Maidenhead, New York: Society for Research into Higher Education and Open University Press

Harris, M. (1996) Review of Postgraduate Education, Bristol: Higher Education Funding Council for England.

HEFCE (2005). PhD research degrees: Entry and completion. http://webarchive.nationalarchives.gov.uk/20100202100434/http://www.hefce.ac.uk/p ubs/hefce/2005/05 02/05 02.pdf (accessed 26 July 2016)

HESA (2016) Students in Higher Education, Cheltenham: Higher Education Statistics Agency

HESA (2014) Students in Higher Education, Cheltenham: Higher Education Statistics Agency

HESA (2013) Students in Higher Education, Cheltenham: Higher Education Statistics Agency

HESA (2012) Students in Higher Education, Cheltenham: Higher Education Statistics Agency

HESA (2000) Students in Higher Education, Cheltenham: Higher Education Statistics Agency

Hodge, Alison (2010). Review of progress in implementing the recommendations of Sir Gareth Roberts, regarding employability and career development of PhD students and research staff. http://www.rcuk.ac.uk/documents/skills/independentreviewhodgepdf/ (accessed 26 July 2016)

Holzinger, K. \& Knill, C. (2005). Causes and conditions of cross-national policy convergence. In: Journal of European Policy, Vol. 12, No. 5, pp. 775-796.

Janson, Kerstin, Schomburg, Harald and Teichler, Ulrich (2007): Wege zur Professur. Qualifizierung und Beschäftigung an Hochschulen in Deutschland und den USA. Münster: Waxmann.

Kehm, Barbara M. (2004): „Developing Doctoral Degrees and Qualifications in Europe. Good Practice and Issues of Concern." In: Sadlak, Jan (ed.): Doctoral Studies and Qualifications in Europe and the United States: Status and Prospects. Bucarest: UNESCO-CEPES, pp. 279-298 
Kehm, Barbara M. (2005): Forces and Forms of Change. Doctoral Education in Germany within the European Framework. Paper presented at the international conference on "Forces and Forms of Change in Doctoral Education Internationally" organised by CIRGE, University of Washington, August (unpublished manuscript)

Kehm, Barbara M. (2006). Doctoral Education in Europe and North America: A Comparative Analysis. In: Teichler, Ulrich (Ed.). The Formative Years of Scholars. London: Portland Press, pp. 67-78.

Kehm, B.M. (2009): „New Forms of Doctoral Education in the European Higher Education Area.“ In: Kehm, B.M., Huisman, J., Stensaker, B. (Hg.): The European Higher Education Area: Perspectives on a Moving Target. Rotterdam, Taipei: Sense Publishers, S. 223-241.

Lisbon Summit (2000): http://www.bolognaberlin2003.de/pdf/PRESIDENCY CONCLUSIONS Lissabon.pdf (accessed 17 June 2007)

OIA (2015). Annual Report 2015. http://www.oiahe.org.uk/media/109675/oia-annual-report2015.pdf (accessed 26 July 2016)

Park, Chris (2005): "New Variant PhD: The changing nature of the doctorate in the UK." In: Journal of Higher Education Policy and Management, Vol. 27, No. 2, July, pp. 189207.

Park, Chris (2006). The end of the secret garden: reframing postgraduate supervision. http://www.lancaster.ac.uk/hr/OED/CPD/rsarchive/files/ChrisPark.pdf (accessed 26 July 2016)

Powell, S. and Green, H. (Eds.) (2007). The Doctorate Worldwide.Maidenhead and New York: Society for Research into Higher Education and Open University Press.

Roberts, Gareth (2002). SET for Success: The Supply of People with Science, Technology, Engineering and Mathematics Skills - The Report of Sir Gareth Roberts' Review. London: HM Treasury.

Robbins, Lionel. (1963) Higher education: report of the Committee appointed by the Prime Minister under the Chairmanship of Lord Robbins 1961-63, Cmnd. 2154, London: HMSO

Simpson, Renate (1983). How the PhD came to Britain. A century of struggle for postgraduate education. Guildford: Society for Research in to Higher Education.

Slaughter, Sheila A. and Leslie, Larry L. (2000): Academic Capitalism: Politics, Policies and the Entrepreneurial University. Baltimore: Johns Hopkins University Press.

Sorbonne Declaration (1998): http://www.aic.Iv/ace/ace disk/Bologna/maindoc (accessed 7 October 2005).

Turner, Gosia (2015). PRES 2015: The research student journey. Higher Education Academy. $\quad$ https://www.heacademy.ac.uk/resource/postgraduate-researchexperience-survey-2015 (accessed 26 July 2016). 
Wildy, Helen, Peden, Sanna and Chan, Karyn (2015). The rise of professional doctorates: case studies of the Doctorate in Education in China, Iceland and Australia. Studies in Higher Education, Vol. 40, No. 5, pp. 761-774. 